\title{
DO YOU KNOW THE LABOUR WARD SISTER?
}

Who is the Labour Ward Sister? Perhaps she deserves above all the title "Midwife Specialist" - continually up-to-date in her knowledge of obstetrics, the "diagnostician" and colleague of the obstetrician; one cannot function adequately without the other.

of course, it is possible to be a specialist midwife without being Labour Ward Sister. So, besides her clinical expertise, what really distinguishes this midwife is her ability to thrive on the challenge of bringing order to the potential chaos which frequently characterises the labour ward. She needs to be an organiser, a psychologist, a mother figure, and in addition goodhumoured. A tall order perhaps, but not to the right person!

A healthy pregnancy, physically, psychologically, emotionally and obstetrically is a prerequisite for a healthy baby who then has a sound start in the adventure of life. It can truthfully be said that good midwifery is the foundation of preventive and promotive health.

The labour ward sister continues the work which has begun during the antenatal period by giving guidance and information that is meaningful to the welfare of the patient and her baby, and by ensuring a safe delivery. The lives of two human beings and the future of one are in her hands. Should her knowledge be lacking, her skill inadequate, her eyes unseeing or her ears unhearing, she could miss vital indications of deviations from the normal, which could have longterm effects on the wellbeing of the mother, the infant, and the family.

"Prevention" is the key word - the Labour ward sister takes on herself the responsibility for early recognition of these deviations, and the initiation of action to ensure a safe delivery.

The excitement and drama of the labour ward appeal to most nurses - and especially to students. There is always an element of anticipation and challenge, balanced by happiness when all goes well or sadness should the outcome be unfortunate. The anticipation is linked to the idea of bringing a new life into the world, while the challenge lies in playing a role in determining the quality of that life, of assisting, guiding and supporting the mother - and the father - to a safe delivery.

An element of danger lies in this excitement and drama, however, and the labour ward sister counters this with sound teaching, not directed only at students, but also drawing in the newly-qualified midwife, as well as the one who has recently returned to practice after a long absence. Staff are never allowed to become stagnant and complaisant as far as their knowledge is concerned, or to develop into mere technicians. The sister accomplishes this by ensuring constant stimulation of staff and students to exchange ideas with doctors and other colleagues at ward meetings and rounds, and by attending seminars and symposiums whenever possible, Of course, this is quite apart from the formal teaching which is part of her reponsibilities as the sister of the labour ward - the Midwife Specialist.

Any service worthy of the name must be subject to regular evaluation, and the labour ward is no exception. The labour ward sister demonstrates her administrative ability by drawing all her staff into the exercise - to evaluate the service, the teaching programme, and themselves - while the really courageous, will include the patient in the evaluation team also.

Evaluation is not a once- or twice-a-year formal institution, but a continuous process to ensure quality.

Finally, the labour ward sister is responsible for bringing trained staff and students to full personal and professional maturity so tht they may always practise with intelligence and confidence as professional individuals in their own right, as part of the team whose main objective is the delivery of a quality service to the mother, the father, the child, the family and to the community.

Yes, the Labour Ward Sister is a special person - do you know her? 